\title{
Income convergence across the U.S. states: further evidence from new recent data
}

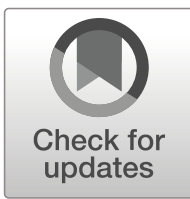

\author{
Rati Ram ${ }^{1}$ \\ Published online: 20 August 2020 \\ (C) Academy of Economics and Finance 2020
}

\begin{abstract}
Noting the analytical and empirical significance of the topic, this research revisits the theme of income convergence across the US states. The work fills several gaps in the existing literature by (a) covering the most recent period 1997-2018, (b) using the official data on real GDP per capita compiled by the US Bureau of Economic Analysis (BEA), (c) explicitly comparing the convergence scenario for 1997-2018 with that for 1977-1997, and (d) placing the observed patterns in the context of Piketty-like propositions about high returns to capital and increasing income inequality. One significant outcome of the exercise is an indication of sigma-divergence across the US states, as reflected in increased standard deviation of logs and coefficient of variation over the period, which correspond to a highly significant positive trend in both. Lack of significant beta-convergence is also of interest as is the contrast in the convergence patterns for 1977-1997 and 1997-2018. A simple explanation for income-divergence is pursued by studying the pattern of changes in $\mathrm{K} / \mathrm{L}$ ratios across states from 2000 to 2015 , and it is found that, contrary to the expected pattern of resource flows, $\mathrm{K} / \mathrm{L}$ ratio tended to increase more in the high $\mathrm{K} / \mathrm{L}$-ratio states than in the low $\mathrm{K} / \mathrm{L}$ areas. This divergence in $\mathrm{K} / \mathrm{L}$ ratio underlies the sigma-divergence in income. The observed pattern may be deemed consistent with Piketty-like propositions about the high and increasing returns to capital which impeded its move to the poorer states with low $\mathrm{K} / \mathrm{L}$ ratio.
\end{abstract}

Keywords US states · Income-convergence · Beta convergence · Sigma convergence

JEL Classification $\mathrm{C} 22 \cdot \mathrm{O} 10$

Rati Ram

rram@ilstu.edu

1 Economics, Illinois State University, Normal, IL 61790-4200, USA 


\section{Introduction}

Study of income convergence across countries or regions is of substantial interest because it can shed light on temporal evolution of income inequality and indicate whether there is support for the recent view about increasing income inequality in the U.S. and other Western countries. Traditionally it has also been used to form an opinion on the relative merits of Solow-type neoclassical growth theories, which imply convergence, and endogenous growth models which carry no such implication. ${ }^{1}$ In addition to numerous studies of cross-country convergence, there has been considerable research on income convergence across the U.S. states. ${ }^{2}$ The early work by Barro and Sala-i-Martin (1991, 1992, 2004) concluded that "overall evidence weighs heavily in favor of convergence" and that "U.S. states provide clear evidence of convergence." These studies led to a kind of "stylized fact" of convergence across U.S. states at a rate of about $2 \%$ per year. ${ }^{3}$ Since then several researchers have investigated the presence or absence of income convergence across the U.S. states, and there is some variability across the studies in terms of the methodology and the conclusions. Among the recent studies, Heckelman (2013) reported tests of beta-, sigma- and stochastic-convergence along with a consideration of the determinants of convergence, particularly the change in capital-labor ratio. Even more recently, Ganong and Shoag (2017) indicated that there has recently been a large decline in the rate of income-convergence across the US states, and provided an explanation in terms of rising housing prices in high-income areas deterring low-skill migration and slowing income convergence.

The main purpose of this paper is to revisit the question about income convergence across the U.S. states so as to make a contribution toward filling the following gaps in the existing studies. First, it covers the most recent period 1997-2018, which no other researcher has considered, and which is important because of the belief about increasing income inequality during the last two decades. Second, it uses official BEA data on state-level real GDP per capita, which has also not been done in any other study. While use of real-income data is obviously appropriate conceptually, it is also empirically important. For example, Ram (2018) has shown that interstate income inequality is much smaller in real income than in nominal income, and Izraeli and Murphy (1997) reported opposite convergence-patterns in nominal and real income for the US states. Third, it documents opposite convergence-patterns in 1997-2018 relative to 1977-1997. Fourth, it places the observed patterns in the context of Piketty-type propositions about high returns to capital and increasing income inequality in the U.S. during the last few decades.

\section{A highly selective summary of existing research}

As noted in the previous section, Barro and Sala-i-Martin $(1991,1992,2004)$ pioneered the research on convergence of per-capita personal income and gross state product

\footnotetext{
${ }^{1}$ Besides other researchers, Islam (2003, p. 309) explains this point.

2 Islam (2003) provides a fine exposition of the cross-country research.

${ }^{3}$ Barro and Sala-i-Martin (2004, p. 472) restate the main conclusion "that the U.S. states tend to converge at a speed of about $2 \%$ per year".
} 
across the U.S. states and indicated the beta-convergence parameter to be around 0.02 . They also noted that parameters for personal-income and state gross product are similar and both indicate convergence at a speed of about 2 percent per year (Barro and Sala-iMartin 2004, p. 472). Since price-level data for states were not available, they used national price deflators to convert the nominal income data into real numbers (Barro and Sala-i-Martin 1992, p. 229). They studied sigma-convergence in terms of crosssectional standard deviation of logarithm and showed its declining tendency until the early 1990s (Barro and Sala-i-Martin 2004, pp. 473-474). After Barro and Sala-iMartin, several researchers have considered the status of income convergence across the U.S. states by using different periods, data sets, and methodologies, and have suggested different conclusions. Only a few of these studies are noted here. First, Izraeli and Murphy (1997) attributed a major weakness in previous studies to improper deflation of nominal income. Working with annual data for 1961-1991, they used state-level cost-of-living numbers generated by private researchers for a few years to convert nominal income into real data, and stated that one finds lack of convergence over the 1970s-1980s in terms of nominal per-capita income, but convergence is observed if nominal per-capita personal income is deflated by cost-of-living estimate for each state. Second, studies by Fousekis (2007) and Holmes et al. (2014) explored stochastic convergence through tests of stationarity for the U.S. states. Third, Heckelman (2013) did a thorough study with data from 1930 to 2009 and found overall sigma- and beta-convergence in cross-sectional tests except possibly for the last three decades. In time-series tests, he found stochastic convergence in about half of the states which indicated beta-convergence also. His probit regressions suggested that convergence is a function of several variables, particularly the change in capital-labor ratio. In a more recent study covering the period 1940-2010 at 10-year intervals, Ganong and Shoag (2017) documented a large decline in the rate of income convergence across the U.S. states during the past 30 years and provided an explanation in terms of a big increase in housing prices in high-income states which deterred low-skill migration and slowed income convergence. They did not find absence of convergence, but noted a slower beta-convergence, which was still highly significant even for the period 19902010 (p. 77). It is notable that they worked mostly with census years and used personal income per capita in constant (2012) dollars (p. 86).

The foregoing narrative shows that there is no study which uses properly-deflated annual income data even though convergence in real and nominal income could indicate very different patterns. It also shows that there is no work which uses data for the most recent 20 years (1997-2018) during which income inequality is believed to have increased considerably. An explicit comparison of the last 20 years (1997-2018) with the scenario for the preceding two decades (1977-1997) is also lacking. Moreover, there is no study that places the observed convergence patterns in the Piketty-type context of high returns to capital and increasing income inequality in recent periods. The present work seeks to address these gaps in the existing literature.

\section{Methodology, data, and the main results}

A well-known model of beta-convergence is estimated by regressing the logarithm of the ratio of final- and initial-year incomes on the logarithm of initial-year income. 
Following the format used by Mohammadi and Ram (2017, p. 405) and numerous other researchers, the income-convergence model may be written as:

$$
\ln \left(\mathrm{Y}_{\mathrm{t}} / \mathrm{Y}_{0}\right)_{\mathrm{i}}=\mathrm{a}+\mathrm{b} \ln \left(\mathrm{Y}_{0}\right)_{\mathrm{i}}+\mathrm{u}_{\mathrm{i}}
$$

where $Y_{t}$ and $Y_{0}$ are the values of income in the last and the first year of the period, In denotes natural logarithm, the subscript i stands for the ith state, and u's are the stochastic error terms. A negative estimate of $b$ implies beta-convergence in the sense that the lower-income states experience a higher relative increase in income.

Sigma convergence is explored by considering changes over the period in (a) standard deviation of logarithm of income (SDLOG), and (b) coefficient of variation of income (CV), which, as Ram (2018) indicates, are two commonly-used measures of cross-sectional dispersion of income. A decline in SDLOG or CV or both implies sigma-convergence while an increase would reflect sigma-divergence.

The basic income variable (SAGDP10N) is real GDP per capita (chained 2012 dollars) taken from BEA (2019a) website. This variable has several appealing features. First, it is the official real GDP per capita measure for each state, and captures the basic price-level adjustment to nominal GDP per capita. (BEA 2017, p. 16) explains that estimates of real GDP by state are derived by applying national-level industry implicit price deflators to the current dollar GDP by state estimates for the detailed industries, and that real GDP by state captures the relative differences in the mix of goods and services that states produce. It is also stated that a Fisher Ideal Index is used to calculate a chain-type quantity index for total GDP by state. ${ }^{4}$ Second, it is the state-level version of real GDP per capita at the country level which has been used in almost all studies of cross-country income convergence, and is thus appropriate for studying income convergence across the US states. Third, it has been used by several well-known researchers, including Barro and Sala-i-Martin (1992, 2004). Fourth, Barro and Sala-iMartin (1992, p. 239) note that "the empirical estimates of $\beta$ for personal income are nearly equal to those for GSP." Last, BEA's real per capita income for states is available only for the period 2008-2017. Therefore, BEA's estimates of real percapita GDP (in 2012 dollars), which are available for the 22-year period 1997-2018, form the basis of the reported estimates.

Table 1 reports the main estimates of equation (1) for the period 1997-2018 covering the 48 contiguous states. ${ }^{5}$ It shows that the initial-income coefficient, which is a measure of beta-convergence, is not statistically significant even at the $10 \%$ level or at any other meaningful level. Therefore, the data provide little evidence in favor of beta-convergence in state incomes over the period 1997-2018. Even aside from lack of statistical significance of the initial-income term, the implied speed of convergence is of the order of $0.6 \%$ per year, which implies a "half-life" of 115 years and is of little significance.

\footnotetext{
${ }^{4}$ BEA (2017) explains construction of real GDP per capita for US states in greater detail.

${ }^{5}$ It is usual to do the analysis for the 48 contiguous states which are likely to have a homogeneous structure. For example, besides other researchers, Barro and Sala-i-Martin (2004, pp. 469, 473) worked with the 48 contiguous states.
} 
Table 1 Estimates of the Beta-Convergence Regression of Equation (1) Contiguous US States, 1997-2018

\begin{tabular}{lllll}
\hline $\mathrm{C}$ & Coefficient of $\ln (\mathrm{Yo})$ & $\mathrm{R}^{2}$ & $\mathrm{NOB}$ & Reg. F \\
\hline 1.547 & -0.123 & 0.03 & 48 & 1.37 \\
$(1.35)$ & $(-1.14)$ & & & \\
Implied speed of convergence: $0.6 \%$ per year & & & \\
\hline
\end{tabular}

Numbers in parenthesis are the t-statistics based on consistent standard errors generated by SAS which was used for all computations. The implied speed of convergence is given by $-\ln (1+b) / t$, where $b$ is the estimate of $\mathrm{b}(-0.123)$ of Eq. (1), $\mathrm{t}$ is the number of years (22) covered by the data, and $\ln$ denotes natural logarithm

While the position indicated by the beta-convergence regression is the starting point, it is more important to consider sigma-convergence which is a more fundamental and interesting concept of convergence. As Islam (2003, p. 314) and several other scholars have noted, beta-convergence is a necessary, but not a sufficient, condition for sigmaconvergence. Although sigma-convergence can be tested through any measure of cross-sectional dispersion of income, coefficient of variation (CV) and standard deviation of logarithms (SDLOG) are two commonly used proxies for such dispersion, and convergence is marked by a reduction in the dispersion.

Table 2 provides an indication of the status of state-level sigma-convergence in income (real GDP per capita) over the period 1997-2018. It shows CV and SDLOG for the initial year (1997) and the last year (2018). Since the end-point values do not provide a complete picture, linear trends in the values of CV and SDLOG over the period are also shown. These have been estimated through the following linear regression:

$$
\mathrm{Y}_{\mathrm{t}}=\mathrm{a}+\mathrm{bt}+\mathrm{u}_{\mathrm{t}}
$$

where $\mathrm{Y}_{\mathrm{t}}$ is the value of CV or SDLOG in year $\mathrm{t}$, $\mathrm{a}$ is the constant term, $\mathrm{b}$ is the linear trend rate for CV or SDLOG, $t$ denotes time (year) and goes from 1 to 22, and u's are the stochastic error terms. The following points may be noted from Table 2.

First, both CV and SDLOG show an increase from 1997 to 2018, indicating income divergence.

Second, the divergent tendency is reinforced by the positive rate of increase, which is statistically significant in both cases. While statistical significance of the increase or decrease in $\mathrm{CV}$ or SDLOG during the period requires a slightly complex procedure, significance of the positive rate of increase is easily tested.

Third, the scenario regarding sigma-convergence is similar to, but not quite the same, as that for beta-convergence which shows a statistically insignificant coefficient. Since sigma-convergence is regarded as more fundamental, one may conclude that the estimates imply income divergence across the US states during 1997-2018. This is one major outcome of the work.

Fourth, it is noteworthy that both CV and SDLOG suggest divergence. There has been some discussion in the literature about the conclusion on sigma-convergence on the basis of changes in CV and SDLOG. For example, Dalgaard and Vastrup (2001) indicated cross-country income to be convergent in terms of CV while 
Table 2 Sigma-Convergence Across the 48 Contiguous US States, 1997-2018

\begin{tabular}{llll}
\hline & 1997 & 2018 & $\begin{array}{l}\text { Linear trend 1997-2018: annual rate of } \\
\text { change (\%) (t-statistic) }\end{array}$ \\
\hline Coefficient of Variation (CV) & 0.170 & 0.187 & $\begin{array}{l}0.46^{*} \\
(4.66) \\
0.65^{*} \\
(8.98)\end{array}$ \\
\hline Standard Deviation of Logarithm (SDLOG) & 0.165 & 0.186 &
\end{tabular}

Values of CV generated by SAS have been divided by 100 to make the scale conformable with that of SDLOG. Numbers in parenthesis are the t-statistics based on consistent standard errors. An asterisk indicates statistical significance at the $5 \%$ level

being divergent in terms of SDLOG. However, Ram (2018, p. 1012) showed in a broader context that both CV and SDLOG are likely to yield the same conclusion in most cases, but SDLOG may show weaker convergence (or stronger divergence) than CV. Table 2 is supportive of that proposition. Although both CV and SDLOG indicate divergence, the rate of divergence is smaller in CV.

\section{A flavor of some comparisons}

While data for the period 1997-2018 indicate fairly persuasively real-income divergence, or lack of convergence, across the US states, it may be of interest to see how the position for an earlier period looks. Although per-capita real GDP data in 2012 dollars (NAICS) are available only from 1997, there is an earlier (SIC) series (BEA, 2019b) in 1997 dollars that covers the period 1977-1997. Table 3 shows the beta-convergence parameter and the CV and SDLOG values from that series. The implication of convergence in real income (GDP per capita) over 19771997 is clear in terms of both beta- and sigma-convergence, and the speed of betaconvergence at about $1.67 \%$ per year is fairly close to the "iron law" of $2 \%$. Therefore, one can say that the phenomenon of income divergence, or lack of convergence, across the US states is relatively recent, and perhaps occurred during the last 20 to 25 years.

It may be recalled that Izraeli and Murphy (1997, p. 570) suggested that while nominal-income data from the 1970s and 1980s indicated lack of convergence, deflation of per-capita personal income by state cost-of-living indexes showed convergence during that period. Tables 1 and 2 show that there is lack of convergence even with the use of real per-capita GDP data over the period 1997-2018.

As previously noted, Ganong and Shoag (2017) indicated decline in income convergence across the US states over the past 30 years. Tables 1 and 2, however, show absence, and not just reduction, of convergence and an indication of divergence during 1997-2018. It should also be noted that they show (p. 77) a highly significant betaconvergence coefficient for the period 1990-2010. 
Table 3 Estimates of Beta-Convergence Parameter, and of CV and SDLOG, Contiguous US States, 19771997: Old Series (1997 dollars) $(N=48)$

A. Beta-convergence: Eq. (1) of the text

Coefficient of $\ln \left(\mathrm{Y}_{0}\right)$ (convergence parameter)

Implied speed of convergence (\% per year)

$-0.284 *$

1.67

$(-3.12)$

B. Sigma-convergence

$1977 \quad 1997$

$\begin{array}{lll}\text { CV } & 0.168 & 0.156\end{array}$

\begin{tabular}{lll} 
SDLOG & 0.164 & 0.153 \\
\hline
\end{tabular}

Numbers in parenthesis are the t-statistics based on consistent standard errors. An asterisk indicates statistical significance at the $5 \%$ level. CV produced by SAS has been rescaled to make it conformable with SDLOG. Since the base years are different, GDP data for 1997 in this table are not comparable to those in Tables 1 and 2.

The cessation of income convergence, and appearance of divergence, across the US states during the last about 25 years is consistent with the widely-shared belief about increased income inequality in the US and other Western countries. ${ }^{6}$ Interstate income inequality is an important component of overall inequality, and increased interstate inequality reflected in income divergence (or lack of convergence) indicates increased overall inequality.

\section{A preliminary exploration of factors affecting convergence}

Heckelman (2013) conducted a study of the factors that affect convergence of a state to the national level. He noted (pp. 1103-1104) that mobility of labor and capital that affects the K-L ratio is expected to be a primary determinant of convergence, and that convergence is expected to be inversely related to the change in $\mathrm{K} / \mathrm{L}$ ratio for the state.

The present study does a preliminary exploration of the change in $\mathrm{K} / \mathrm{L}$ ratio as a major factor behind interstate convergence or divergence. For each state, real capital stock for 2000 and 2015 is taken from El-Shagi and Yamarik (2019, pp. 1417-1418), and employment for these years is taken from Bureau of Labor Statistics website (2020). To judge the pattern of change in $\mathrm{K} / \mathrm{L}$ ratio from 2000 to 2015 , which period is similar to 1997-2018, change in (logarithm of) $\mathrm{K} / \mathrm{L}$ ratio from 2000 to 2015 is regressed on (logarithm of) the ratio for 2000. The coefficient of the log-ratio for 2000 is noted to be positive with a t-statistics of 7.54 which carries high statistical significance. This shows that $\mathrm{K} / \mathrm{L}$ ratio over the period across the states diverged instead of converging which would be expected on the basis of resources moving from high K-L ratio to the low-ratio states. The divergence in $\mathrm{K} / \mathrm{L}$ ratio is likely to be a major factor behind the divergence reflected in increased income-dispersion. ${ }^{7}$ Although an

\footnotetext{
${ }^{6}$ The discussion of increased inequality has been pervasive for several years. Piketty (2017) is a widelydiscussed treatise on the topic.

${ }^{7}$ Additiona details about the $\mathrm{K} / \mathrm{L}$ ratios are available from the author.
} 
explanation for the unusual pattern of resource flows is outside the scope of this paper, the pattern seems consistent with a Piketty-type proposition about high and increasing returns to capital, which impeded its flow to poorer states, and which may also cause income-divergence to continue. If Covid-19 has had a greater adverse impact on poorer states, that might accentuate the tendency towards income divergence across the US states.

\section{Concluding thoughts}

This study revisits the theme of income convergence across the US states, which is important both conceptually and empirically. The work fills several gaps in the existing literature by (a) using official BEA real-GDP data, (b) covering the most recent period 1997-2018, (c) comparing the scenario for 1997-2018 with that for 1977-1997, and (d) placing the study in the context of Piketty-type propositions about increasing income inequality in the US. One significant outcome of the exercise is an indication of sigmadivergence across the US states, as reflected in increased standard deviation of logarithms and the coefficient of variation, and a positive trend in both. Lack of significant beta-convergence is also of interest as is the contrast in the convergence patterns for 1977-1997 and 1997-2018. A simple explanation for income-divergence is pursued by studying changes in $\mathrm{K} / \mathrm{L}$ ratios across states from 2000 to 2015 , which show that, contrary to the expected pattern of resource flows, $\mathrm{K} / \mathrm{L}$ ratio tended to increase more in the high $\mathrm{K} / \mathrm{L}$-ratio states than in the low $\mathrm{K} / \mathrm{L}$ areas. This divergence in $\mathrm{K} / \mathrm{L}$ ratio underlies the observed sigma-divergence in income. While an explanation for the unusual pattern of resource flows is beyond the scope of this work, the observed pattern seems consistent with Piketty-type propositions about the high and increasing returns to capital, which impede its move from high-income states to poorer states with lower $\mathrm{K} / \mathrm{L}$ ratios. That consideration implies that income divergence is likely to continue. Also, to the extent the recent prevalence of coronavirus might have affected the poorer states more, it is likely to accentuate income divergence across the states.

Acknowledgements Perceptive comments on an earlier version from an anonymous reviewer are gratefully acknowledged. The usual disclaimer applies.

\section{References}

Barro R, Sala-i-Martin X (1991) Convergence Across States and Regions. Brook Pap Econ Act 1:107-182 Barro R, Sala-i-Martin X (1992) Convergence. J Polit Econ 100:223-251

Barro R, Sala-i-Martin X (2004) Economic Growth, 2nd edn. MIT Press, Cambridge

Dalgaard C-J, Vastrup J (2001) On the measurement of $\sigma$-convergence. Econ Lett 70:283-287

El-Shagi M, Yamarik S (2019) State-level capital and investment: Refinements and update. Growth Change 50:1411-1422

Fousekis P (2007) Convergence of Relative State-Level Per Capita Incomes in the United States Revisited. J Region Analysis Policy 37(2):80-89

Ganong P, Shoag D (2017) Why has regional income convergence in the U.S. declined? J Urban Econ 102: 76-90 
Heckelman JC (2013) Income convergence among the U.S. states: Cross- sectional and time series evidence. Can J Econ 46:1085-1109

Holmes MJ, Otero J, Panagiotidis T (2014) A Note on the Extent of U.S. Regional Income Convergence. Macroecon Dyn 18:1635-1655

Islam N (2003) What Have We Learnt From the Convergence Debate? J Econ Surv 17(3):309-362

Izraeli O, Murphy K (1997) Convergence in State Nominal and Real Per Capita Income: Empirical Evidence. Publ Finance Rev 25(6):555-576

Mohammadi H, Ram R (2017) Convergence in energy consumption per capita across the US states, 19702013: An exploration through selected parametric and non-parametric methods. Energy Econ 62:404-410

Piketty T (2017) Capital in the twenty-first century. Belknap Press, An imprint of Harvard University Press, Cambridge

Ram R (2018) Comparison of cross-country measures of sigma-convergence in per-capita income, 1960-2010. Applied Economics Letters, 25:1010-1014.

U.S. Bureau of Economic Analysis (2019a) Per capita real GDP by state (Chained 2012 dollars), Table SAGDP10N, accessed June 2019

U.S. Bureau of Economic Analysis (2019b) Per capita real GDP by state (Chained 1997 dollars). Table SAGDP10S, accessed June 2019

U.S. Bureau of Economic Analysis (BEA) (2017) Gross Domestic Product by State Estimation Methodology, Washington, DC

U.S. Bureau of Labor Statistics (2020) States and selected areas: Employment status of the civilian noninstitutional population, January 1976 to date (Accessed May 2020)

Publisher's note Springer Nature remains neutral with regard to jurisdictional claims in published maps and institutional affiliations. 